\title{
The Idea and Essence of Electronic Tourism
}

\author{
Natalya Mikhailovna Karaulova
}

Aleksandr Jurjevitch Gavrilov

Federal budget educational institution of higher education, "Russian state university of tourism and service" Russia Moscow region, 141221, Pushkin district, village Cherkizovo str. Glavnaya, 99

\section{Doi:10.5901/mjss.2015.v6n5s1p211}

\section{Abstract}

In the article there is investigated the idea of electronic tourism, proved its applicability for tourist industry on the modern stage of development. Peculiarities of selling tourist product define necessity to use relevant information support. There are defined the advantages of global information net Internet for the tourist industry. There are examined technologies, used in electronic tourism. Three is hold analyses of development of electronic tourism in Russia.

Keywords: Tourism, tourism business, tourism product, information technologies, electronic tourism, electronic sells, Internet.

\section{Introduction}

Tourism is one of the high profitable, biggest and the most dynamically developing branches of global economy. The successful forming of tourism effects such sectors of economy as communication and transport, trading, agriculture, construction, producing of national consumption products and others. Due to unequally rapid rate of expansion of tourism it is considered to be economic phenomenon of the last century and it is forecasted to have the same important role in the future century. According to forecast of Global Tourist Organization (UN VTO) in the 21 century the growth of tourist industry would become non-convertible, and by 2020 number of international tourist visits would become 1,6 bln. units (Zaitseva and Chernikova, 2013).

Due to tourism modern person can implement the idea to learn something new, go long distances to see historical and culture objects worth seeing, new regions. From another side - tourism is the high profitable business, as the experience of the more successive in this sphere countries show: people voluntary spend their money for voyages.

Russian market of tourist services, that was made mostly spontaneously in general with absence of coordinating center is in crisis and Russian objects, in spite of certain recreation ability of the country are still not included in international tourist catalog (Kortunov and Fedulin, 2013). This situation was done because of absence of true and reliable information about state of the market and usual for foreign buyer of tourist product of service, based on all possibilities, provided by modern communication media (Novikova et al., 2013). Today the process of making and sending of tourist groups without use of information technologies is of low effectiveness.

Tourist companies and institutes for managing tourism, that go to the international market, face in their activity with problems of studying new information technologies, that are the necessary term of international integration and modern concept of tourism business as information saturated sphere (Kortunov et al., 2014).

Now in connection with it the analyses of electronic system on the tourism, investigation of main spheres of implementing information technologies and development of recommendations for implementing of information systems is especially actual.

\section{Method}

Method part is for description of used in the process of investigation media. For forming summaries and conclusions there were used concepts and hypotheses, defined in projects about development of tourism. At development of system and theoretical aspects of the work there were used the provisions of economic theory and general theory of systems (Karaulova and Sizeneva, 2014). Argumentation of theoretical ideas and conclusions was used with the help of general science methods of investigation and principles of dialectic logics.

Information base of investigation made up Russian and foreign authors, regulations as well as data of printed 
media

Analyses of references showed that at present moment there are no steady definitions. While forming the category it is useful to use method of system analyses. The system is dozens of elements, interconnected with each other, and they form certain entity and union. When we define the idea as system composition of aspects of its ideas it is correct to examine it as abstract system. The idea that is abstract system is formalized, it is defined by function of accumulation of specifications, and can be examined with the help of tools, suggested by V. Sadovskiy (Sadovsky, 1978), and further developed by A. Dyachenko (Dyachenko, 1996). In this case the system idea should be described as:

$I=f(A, B, C, D, E, F)$

where: $A$ - is specification of initial components of the system;

$B$ - specification, describing combination of initial components (dozens, plurality, group, complex);

C - specification, defining the system forming connections and relations between the initial components (cooperation, cohesion and so on);

$D$ - Specification, defining the integrative specification of system, due to which it is provided its existence and functioning

$E$ - specification of functional direction of system development;

$F$ - specification of conditions at which it is able the existence and functioning of the investigated system.

This formula (1) contains the full set of specifications, necessary for description of the system being investigated. But, as a rule, the idea, used as basis for analyses doesn't have the set of specifications, mentioned above. System analyses of combination of the well known definitions will allow to eliminate the indicated problem and make the synthesis of selective idea, meeting the well known presentations.

\section{Results}

Term "electronic technologies" was used to define the most modern improvements in mechanisms and methods, which were used for collecting, processing, evaluation, storage, distribution and implementing of information. IT solutions are able to impact on procession activity, sphere of services, employment of people and life of the people of the universe in general, due to developments in microelectronics.

The idea "electronic development" itself appeared in the last decade of the $20^{\text {th }}$ century while development of informatics (Kharitonova and Chkhikvadze, 2014). The main identification of information technologies is that in them product and subject of labor is information, and work equipment is the communication media and computers. Thus information began to be considered as fully features production resource as the other material resources.

Manufacturing of information and its upper level - knowledge - greatly effects on transformation of old and forming of new technologies. Recently the information technologies and tourism seemed to be incompatible partners. Now this two ideas so interconnected with each other that there arose the new type of tourism - the "electronic tourism".

Tourism is selling of services, including the following:

- different and complex work, from points of view of the producer and the buyer;

- inner changing and unseen work;

- information saturated work (Zaitseva, 2013).

These features of tourism define the ability to implement information technologies to the tourist sphere.

Subject and object structure of interrelation as for selling and buying of tourist product includes producers of tourist services, that act within system of government and commercial organizations (for example, vehicles, hotel and tourist agents and so on) (Karaulova and Sizeneva, 2014). Producers of tourist services are classified as for certain categories of suppliers (hotels, air flight companies, service at tourist destination, renting of vehicles), whole sales companies (tour operators) and retail sale companies (tour agents). Tourists (suppliers) are the last step of the whole tourist system.

As for regulating of company business, advertizing, taxation (Karaulova et al, 2013) and promoting (Guschina et al, 2014), here information plays the main role in the process of connecting the suppliers of tourism services to the united social and economic system. That is the information that united different suppliers within one tourist branch. Thus the important individual feature of tourism is that the interconnection between the suppliers and manufacturers is done not by the product, but by the flows of information.

These information flows suggest as transportation of certain data, as well as payments and services. Services, such as accommodation in the hotel, tickets for the air flight are not exhibited physically and not visually inspected at selling at destination points (Zaitseva, 2013). The only guide to the quality and presence of the product is the information. Thus, providing with correct information and the velocity of distributing it is as principal for functioning of tourist business, 
as actual presenting its cervices to the customers. This circumstance contributed that the information technologies became the important tool is the activity of all organizations of the tourism. Thus at the beginning of $90^{\text {th }}$ all companies, independent on geography, suggested product and size, overcame the severe process of reorganization of business (Orlova, 2014).

Within the characteristic parameters of information technologies, that have the strategic sense for development of society it is practicable to point out the most important ones.

First of all the electronic technologies allow to activate and successfully implement the information resources of the company, that now are the most important strategic factor of its development. The experience shows, that activating, distribution and effective implementing of information resources (scientific developments, knowledge, inventions, experience and technologies) allow to get the great saving of other resources (energy, raw materials, equipment and materials, natural resources, people's recourses, public time).

Second, electronic technologies allow to improve and almost in all variants automotive information processes that for the last years play greater role in the life activity of the human society (Kortunov and Fedulin, 2013).

1. It is commonly known, that forming of civilization is in the direction of development of information society, in which the subjects and objects of labor of the most working people are not the material values, but mostly the scientific knowledge and information. Now in most developed states the most part of working people in their activity more or less is connected with the processes of preparation, keeping, processing and delivering of information and because of this it has to study and actually use the electronic technologies, belonging to this processes. (Zubakova et al., 2014).

It should be pointed out, that electronic technologies play an important role in providing electronic interrelation between people, and also in systems of distributing and preparation of mass information. This media rapidly assimilate by culture of the community as they make great conveniences as well as take off almost all processing, public and domestic difficulties, created by processes of integration and globalization of the world community, expanding of international inner culture and economic linkages, migration of population and its more dynamic movement on the planet.

Together with traditional communication media (telegraph, telephone, television and radio) more wide are used the systems of electronic telecommunications, e-mails, fax broadcasting of information and other types of media. In its turn the net electronic technologies represent the perspective and actual direction of development of electronic technologies. They are to provide exchange of information between certain users of the information and calculation systems, as well as creation for them the ability of cooperative use of the distributed information recourses of the company, getting of reference and other information from different types stipulated information funds (Orlova, 2014).

It is necessary to investigate the global information net Internet, that is the center of interests of professionals of information technologies, sole proprietors and users. Internet is not the single computer net, but ten thousands of the united global and local state nets, linked with each other. Among Russian commuter nets to the Internet are switched on glasnet, relcom and almost all the other. At present moment the global net includes more than 40 million subscribers in more than 100 countries of the world on all 7 continents and number of subscribers of the net doubles every ten months.

Exchange of information via net per year increases in 10 times. Every second via net are delivered more than 4000 electronic notices. Global computer net is developing so rapidly that per year number of its prescribers and size of information resources actually double.

Obviously that tourist business can not stay aside of this bum. Just at the middle of $90^{\text {th }}$ in Internet arose thousand of independent sections of air flight companies, tourist agencies, dozens of systems for booking of the tourist services. In 2013 with the help of Internet there were sold tours and associated services for the sum exceeding 200 mlrd. US dollars. So agencies need to consider Internet as obligatory element of its work. Global net provides the excellent information impact and adds to the usual ones the new channel for selling tourist services - electronic one (Zaitseva, 2013). At the present moment half of the all income, generated via Internet, comes via branch of tourism and travelling. Nearly $60 \%$ of users, which use Internet, look for tariffs of air companies and hotels and information on presence of vacant places.

Global net has some unavoidable advantages:

- mass audience (approximately 35000 buyers visit the most popular server for the tourism travelweb, at which more than 170 hotels are presented).

- comparatively low indirect costs and implemented efforts for the sellers and the clients.

- comfort (the constant excess to the net for personal users).

This advantages of Internet as well as ability of timely updating of the information are used also by tourism companies, for which the net opens the real advantages for selling tourist goods in on-line regime and their advertisement, as well as promoting of sales.

At the modern practice in the tourism branch there is vast usage of innovation electronic, technologies within the 
sphere of reserving, booking, internal communicative nets, smart cards, multimedia systems, information systems of management and so. There is unavoidable of crossing of telecommunication and information problems and media for their settling. It is mostly about Internet as the greatest information and telecommunication media (Kortunov et al., 2014).

Subjects of telecommunication systems are:

1) communication providers that actually provide infrastructure abilities with the full set of universal services; domination over national segment of Internet belongs to the country on which territory it is located;

2) Providers of services of excess to Internet, global distribution systems are the providers and owners of certain part of pass on technologies and who are distributing them among the users and providers of information;

3) Providers of information - owners of information and trading portals and servers;

4) Users.

Modern telecommunication systems and computers reduce time and expenses for communication, state borders don't influence on their implementation, they contribute to increasing of distribution of knowledge globally. Computers and Internet contribute to total reorganization of business - from purchase of production means and sales of goods to decentralization of management and out sorting. Information technologies give the possibility to trade some services that previously were out of sales turnover the same way as with material goods. Nowadays there is lack of statistical data with the help of which we can evaluate the actual economic effect from using of information technologies. Statistic is not enough adapted to changing of volume of output in the XXI century. It is the most difficult to make measurements in the sphere of services, and information services and Internet only worsened this problem, as the most part of profit of their use takes the form of higher quality of products, conveniences and more advanced service of consumers. Information technologies allow more simply and with fewer expenses suggest personalized goods and services. But official statistics can not take into consideration profits, connected with broader selection, which the users have at present moment. The indexes of gross products are not controlled and non-material gain from growth of consumer's satisfaction. All technological revolutions are joined not only with profit, but also with risks. Any technological progress leads to restriction of working places and professions, but in stead of those new professions appear. Implementation of information technologies increases demand for specialties, requiring certain qualification and good education. Economics becomes more and more dependant on knowledge.

But the main impact on tourist markets does the technologies of promoting tourist services and goods, which is advertizing and marketing of tourist companies in Internet. Representation of company in Internet guarantees the tourist company the possibility of expanding of possible client's base (Korneev et al., 2014).

To the new spheres of distribution and implementation of the tourist product belong to:

- Making of Internet-sites of tourist companies,

- portals,

- booking system

- electronic cabinets and so on.

\section{Discussion}

One of the main perspective developments are considered to be electronic cabinets, with the help of which any who has account on credit plastic card or in electronic payment systems, can pay for aircraft tickets, bye a tour and so on.

Besides that electronic technologies make a great influence on tourism and social and cultural service due to computer reservation system. These systems appeared in the middle of pest century to optimize the booking process of air tickets on-line. This system allows to decrease time of service, increase quality of supplied services, contributes to sizes of income and deals and so on. At the Russian market the most popular are systems of electronic booking galileo, amadeus, worldspan, sabre and others.

One of the main directions of implementation of tourist electronic technologies is implementation of multimedia technology. First of all they are tourist reference books, collectors, brochures, issued on CDs and in Internet (Yudin et al., 2014). Electronic media represent different information on continents and countries. Thus electronic collectors and reference books perform as reference and informative function, safe time to search data, are comfortable in use.

At present moment when the number of Internet users increases more and more tourist operators and tourist agents pay attention to development of online representative office (Doronkina et al., 2014), considering this direction to be perspective and even necessary. We should pay attention to quality, correctness and actuality of information, presence of coordinates, ability to make request and leave a feedback. Development of directions for improvement use of Internet-technologies in the field of tourism is a certain sphere of interests for some tourist companies. As well as for 
tourist branch of Russia in general, contributing to increasing of tourism attractiveness.

The most full collection of tourist sites, popular with Russian users is certainly the section "Round the world" of the catalogue "Mail.ru" (www.mail.ru). Here are presented references for more than 4000 web-sites, devoted to tourism, travelling, countries, health resorts, tourist companies, and they are grouped in several dozens of subcategories including ethnographical peculiarities, that significantly easies search of resource they need (Gavrilov, 2014).

But the most visited by potential tourists is the section "Travelling" by rating-classifier Rambler (www.rambler.ru). Here all pages are sorted according to their popularity that is the more people have seen this of that page on Site, the higher place in rating it has, the easier it can be found.

Site "Pososhok" (pososhok.ru) helps the travelers and those who like adventures, it provides information on price of air tickets, information about air flights, dates of departure and arriving. "Pososhok" cooperates with bog global air companies: Lufthansa, FinnAir, Alltalia, Delta, British airlines and others. Instructions for booking the ticket is quite simple: at the site pososhok.ru there is the form to be filled in, with indicating data, planned dates of air flight, direction and amount of passengers. The system will select all suggestions about this request and the client is able to choose optimal variant.

Site Booking.com is the system of booking hotels all round the world. Russian users have the possibility to use Russian language variant, which defined the popularity of this resource with Russian travelers. At the site there is simple form for looking for hotels all round the world and notice how to book a hotel correctly (Ulyanchenko and llkevich 2014).

Besides catalogues, tourist sections are met at the entertaining sites, on megaportals, for example, on www.gala.net, www.emax.ru. But information, presented at these sections has less volume and quality as on specialized tourist sites.

Tourist portals can be investigated as online advertizing areas, which should contribute to sales of services provided by advertisers - tourist operators and tourist agencies. Source of portals profit can be as banner advertisements and paid placing of information on tourist companies and their suggestions, as well as commission charges, got from the tourist company for the fact of order from server.

At the portals we can book a tour via special developed form (feedback) or order information on suitable suggestion via e-mail. As a rule, such suggestions look like lines with noting sales company, health resort, category of the hotel, type of transport, and additional services at the tour, minimal or maximal price and so on. It should be noted, that the tourist company offices can himself register and change his tours online. Some resources suggest the method of ordering tour online, the ability to install price-lists in the programs of tours, white expanded feedback and so on. But the advertizing providers in this case don't need to have their page in Internet, they only need to indicate their e-mail and phone number.

Conferences (forums) have the same success on the tourist sites. In them any Internet user can express his opinion on work of any tourist company, advice with the best place for rest, ask the audience for the best action in this or that situation, when he chooses the hotel package, health resort and tourist company and so on.

Server www.travel.ru exists from 1997 and contains database of tourist agencies of Russia and other countries, as well as lost of suggestions of great variety of tours. In July 1999 there was joined the "Traveler's archive" - big Russian language library with information on countries, their culture and history, stories about voyages and many other things to the server. In the "Traveler's archive" there are more than 5 thousand articles about 199 countries.

Server "100 roads" (www.tours.ru) was made by company "Arim-Soft" and exists from 1996. The first variant of site was demonstrated on the spring tourist expedition Mitt-96 and since then he takes part in all big tourist events. The constant audience is represented mostly by tourist companies, which visit server minimum one time a week. This server is the most informative, as it contains the database on tourist companies in more than 150 countries, 100 thousand objects in all continents and provides the possibility to get advice, relating to legal aspects of tourism and so on. There is a section of last minute tours. There are given descriptions of more than 2 thousand hotels.

Server "100 roads" is one of the 60 most famous sites of Russian Internet. He was considered as the most investments attractive project from more than 100 Russian sites participants and awarded the premium "Leaders of Russian tourist business-2001" at the nomination "The best site of the year in the area of tourism".

Server "Travelling catalogue" (www.turizm.ru) is developed by the company "Bureau of Internet-Marketing" in February 1998 and is also one of the most popular and often visited tourist portals.

Server www.votpusk.ru conyains information about the countries, companies and also suggestions on leading tourist companies of Russia and foreign countries; here is also given information on companies, who claim a visas and foreign passports, sale and booking of air and railway road tickets. This server suggests also the advertizing services. The peculiarities of the system are: simplicity of service and editing; completeness of presenting information (placing of non restricted amount of this information on programs of advertisement providers - description of excursions, hotels, 
photo materials, pricing tables and so on); individual approach, control of effectiveness within the whole period of placing the advertising note and moderate and flexible pricing policy.

"Tourist guide" (www.turgid.ru) is the specialized information and searching catalog with weekly renewed news and events. There are suggestions of leading tourist companies, provided the ability of booking tourist routs via Internet, there is information on clamming for visa, foreign passports, insurances and about travelling abroad and so on.

"Last minute tours shop" (http://mgp.ru/) contains information on last minute tours and those companies, which sell them, as well as vast reference information on countries and health resorts, description of hotels, tourist news and so on.

At site "All hotels of Russia" (www.all-hotels.ru) there is given information on hotels of Russia and foreign countries. After registration and getting a pass word it is possible to book places in hotels via e-mail, as well as via fax with certifying by e-mail. At the tourist agencies request within 24 hours it is chosen the best variant of accommodation with additional discounts.

Reference tourist service "The Red Phone" (www.redphone.ru) contains information on tourist companies, description of tours, list of companies, suggesting services for clamming for visa, foreign passports and buying of air tickets, as well as information on countries, towns and health resorts.

The most part of Russian tourist operators are represented in the Internet more or less. The main groups of tourist operators site are: visit card, Web-window and system "Tourist operator - tourist agent".

It to try to classify sites of tourist agencies, then hierarchy would look like the sites of tourist operators: visit card, Web-window and tourist electronic shop.

The main peculiarity of tourist electronic shop is in detailed description of each tour, hotel at the certain data with the respective prices it is suggested to order certain tourist package. But presenting of this scope of information is impossible without use of online database on tours. Poor system of Internet payments doesn't allow now to but tour via Internet, but we can choose the tour, with certain hotel and make the booking.

As the effectively working electronic shop we can show the server of shops of last minute tours net (http://mgp.ru/). The visitors can choose a good tour for them almost in any country of the world at the low cost price, give an application for the selection of tour, get acquaint with description of popular health resorts and hotels, find a companion for the tour (now this type of services is widely spread), book and buy air tickets at the best prices, get answers to the popular questions, study the rights of a tourist, and also learn cases from practice, order a taxi in Moscow, get an advice from experienced tourists.

This server also suggests the twenty-four-hour telephone service of helping tourists abroad. All offices work at the same price and use the general constantly renewable database of suggestions, that forms the certain requirements to the specialists level of education (Khanbabaeva and Novikova, 2014). That is why in order to buy last minutes tours or just good tours at the best price, it is necessary to learn the address of the nearest branch. In every there is provided the equally high level of service, big range of suggestions and best prices.

Speaking about Russian market of information technologies it should be noted, that today it is on the stage, when most tourist companies are ready to provide all information the client needs online, but Russian consumer is not ready to use Internet-technologies for him. The exclusion are central regions of Russia, where the share of potentially financially reliable users of Internet makes up at about $70 \%$.

\section{Conclusion}

For the present moment in the business of tourism found vast use the innovative electronic technologies in the sphere of reserving, booking, internal communication nets, smart cards, multimedia systems, information systems of management and so on.

One of the most effective mechanism for collecting, classification and analyses of information as for tourist branch and also complex promotion of tourist and natural territories is the electronic tourism. Analyzing the value of information technologies for modern development of the community, we can make proved conclusions that their role is strategically important, and value of these technologies is the nearest future would increase. They are the technologies to define the main role in the sphere of technological development of the country. Prove for this conclusions is the row of uncial parameters of the information technologies (availability, results bringing ability), which move them to the place of high priority comparing with social and production technologies.

In the article there are investigated the most popular ways to use media of global information net Internet for organization and making of a tour. In Russia electronic tourism was distributed only recently and it is dynamically expanding, facing the problems of growing market. Due to obvious advantages of implementation of technologies of electronic tourism the investigations about this theme are quite actual. The authors are interested in holding of an 
additional, more detailed analysis of electronic tourism development in Russia and its perspectives.

\section{References}

Doronkina, I.G., Borisova, O.N., Malyutin, G.V. and Gazilov, M.G. (2014). Ecotourism in Community Environment. World Applied Sciences Journal, 30, 35-36. DOI: 10.5829/idosi.wasj.2014.30.mett.18.

Dyachenko, A. (1996). Theory of systems and some economic problems. City of Volgograd. Volgograd state university publishing house.

Gavrilov, A.Y. (2014). Bajkonur space launching site: historical and legal aspect of Russian-Kazakh relations. Life Sciences, 11 (5), 469472. http://www.lifesciencesite.com//sj/life1105/067_24348life110514_469_472.pdf

Guschina, E.G., Morozova, I.A. and Vitaljeva, E.M. (2014). The Role of the Concept of Advertising in Interaction Between the Market for Education Services and the Sphere of Business. World Applied Sciences Journal, 31(11), 1979-1982. DOI: 10.5829/idosi.wasj. 2014.31.11.1705.

Karaulova, N. M. and Sizeneva, L. A. (2014). Elementary Unit of Mechanism of Interests Implementation of Economic Intercourse Subjects. World Applied Sciences Journal, 30 (10), 1380-1383. DOI: 10.5829/idosi.wasj.2014.30.10.14177.

Karaulova, N.M., Sizeneva, L.A. and Likhovidova, E.P. (2013). Tax Reforms Mechanism Essence. World Applied Sciences Journal, 27 (Education, Law, Economics, Language and Communication), 366-370. DOI: 10.5829/idosi.wasj.2013.27.elelc.74.

Khanbabaeva, Z.M. and Novikova, N.G. (2014). Peculiarities of Specialists' Training for Regional Tourism Industry in Terms of Graduates' Self-Assessment. World Applied Sciences Journal, 30, 25-27. DOI: 10.5829/idosi.wasj.2014. 30.mett.14.

Kharitonova, T.V. and Chkhikvadze, N.A. (2014). Research of Competence-Based Tourism Educational System's Conformity with Requirements of a Modern Business-Society. World Applied Sciences Journal, 30 (Management, Economics, Technology \& Tourism), 22-24. DOI: 10.5829/idosi.wasj.2014.30.mett.12.

Korneev, A.A., Rudneva, M.Y. and Sokolova, E.Y. (2014). Analysis of European Experience of Motoring Tourists' Camps Creation. World Applied Sciences Journal, 30, 01-02. DOI: 10.5829/idosi.wasj.2014.30.mett.1.

Kortunov, V. and A. Fedulin, A. (2013). A critical analysis of the impact of elecommunications on the worldview of Russian society. Middle East Journal of Scientific Research, 15(10), 1389-1395. DOI: 10.5829/idosi.mejsr.2013.15.10.11614.

Kortunov, V., Ananyeva T., Platonova N. and Chudaykina, G. (2014). Fundamentals of Professional Ethics for Travel Service Employees. World Applied Sciences Journal, 30, 20-21. DOI: 10.5829/idosi.wasj.2014.30.mett.11.

Kortunov, V.V., Fedulin, A.A. and Kostovarova, V.V. (2014). Ethics of Hotel Business: Practical Aspects. World Applied Sciences Journal, 30, 43-44. DOI: 10.5829/idosi.wasj.2014.30.mett.22.

Novikova, N.G., Sakharchuk, E.S. and Ilkevich, S.V. (2013). The Factors of Russia's Low Competitiveness as a Medical Tourism Destination. World Applied Sciences Journal, 27 (Education, Law, Economics, Language and Communication), 251-255. DOI: 10.5829/idosi.wasj.2013.27.elelc.52.

Orlova, N.V. (2014). Institutional bases of assurance of reliability and stability of Non-State pension funds. Life Science Journal, 11(8), 558-562. http://www.lifesciencesite.com/lsj/life1108/079_24898life110814_558_562.pdf

Sadovsky, V.N. (1978). Background of general theory of systems. City of Moscow, Nauka.

Ulyanchenko, L.A. and Ilkevich, S.V. (2014). Sustainability Issues in the Russian Hotel Industry. World Applied Sciences Journal, 30, 7879. DOI: 10.5829/idosi.wasj.2014.30.mett.33.

Yudin, M.V., Sakharchuk, E.S. and Gozalova, M.R. (2014). The State Information Policy as a Condition for the Formation of Social Competences of the Students (Case-Study: Higher Schools of Tourism). World Applied Sciences Journal, 30, 32-34. DOI: 10.5829/idosi.wasj.2014.30.mett.17.

Zaitseva, N.A. (2013). The forecast of development of the hotel business in Russia as a promising direction of business expansion of international hotel chains. Middle East Journal of Scientific Research, 14 (3), 328-334. DOI: 10.5829/idosi.mejsr.2013.14.3.2048.

Zaitseva, N.A. and Chernikova, L.I. (2013). Features and prospects in the development of the services provided in the field of travel insurance. Middle East Journal of Scientific Research, 16 (7), 996-1002. DOI: 10.5829/idosi.mejsr.2013.16.07.11964.

Zubakova, N.N., L.A Sizeneva and Karaulova, N.M. (2014). Tourist resources as object of theoretical investigations. Classification of tourist resources. Life Science Journal, 11(8), 616-619. http://www.lifesciencesite.com/lsj/life 1108/091_24971life110814_616 619.pdf 